\title{
Researches on the Constitutive Models of Artificial Frozen Silt in Underground Engineering
}

\author{
Yugui Yang, ${ }^{1,2}$ Feng Gao, ${ }^{1,2}$ Hongmei Cheng, ${ }^{1,2}$ Yuanming Lai, ${ }^{3}$ and Xiangxiang Zhang ${ }^{1,2}$ \\ ${ }^{1}$ State Key Laboratory for Geomechanics and Deep Underground Engineering, China University of Mining and Technology, \\ Xuzhou 221116, China \\ ${ }^{2}$ School of Mechanics and Civil Engineering, China University of Mining and Technology, Xuzhou 221116, China \\ ${ }^{3}$ State Key Laboratory of Frozen Soil Engineering, Cold and Arid Regions Environmental and Engineering Research Institute, \\ Lanzhou 730000, China \\ Correspondence should be addressed to Yugui Yang; ygyang2009@126.com
}

Received 19 February 2014; Revised 31 May 2014; Accepted 1 June 2014; Published 17 June 2014

Academic Editor: Luigi Nicolais

Copyright (C) 2014 Yugui Yang et al. This is an open access article distributed under the Creative Commons Attribution License, which permits unrestricted use, distribution, and reproduction in any medium, provided the original work is properly cited.

\begin{abstract}
The researches on the mechanical characteristic and constitutive models of frozen soil have important meanings in structural design of deep frozen soil wall. In the present study, the triaxial compression and creep tests have been carried out, and the mechanical characteristic of frozen silt is obtained. The experiment results show that the deformation characteristic of frozen silt is related to confining pressure under conventional triaxial compression condition. The frozen silt presents strain softening in shear process; with increase of confining pressure, the strain softening characteristic gradually decreases. The creep curves of frozen silt present the decaying and the stable creep stages under low stress level; however, under high stress level, once the strain increases to a critical value, the creep strain velocity gradually increases and the specimen quickly happens to destroy. To reproduce the deformation behavior, the disturbed state elastoplastic and new creep constitutive models of frozen silt are developed. The comparisons between experimental results and calculated results from constitutive models show that the proposed constitutive models could describe the conventional triaxial compression and creep deformation behaviors of frozen silt.
\end{abstract}

\section{Introduction}

In recent years, frozen soil as an engineering material has been used in many engineering constructions, such as metro engineering, tunnel construction, mine shaft, and other engineering activities in underground, because it can withstand structural support to prevent the deformation of unfrozen soil near to mining cavities [1-3]. The stability of frozen soil wall is susceptible to hazards induced by the deformation behavior during and after constructions. The researches on deformation behavior of frozen soil have large significance to the stability of frozen soil engineering, which was valuable to guide the frozen soils in engineering constructions. Constitutive models, which are used to reflect the response behavior of natural and manufactured materials under different mechanical and environmental conditions, are the bases of describing the mechanical behavior of materials under external load and are expressed in terms of stress, strain, and internal state variables which describe the effect of the previous load history on the current properties [4]. Moreover, modeling can be used as a research tool for a more fundamental understanding of physical phenomena that can result in the development of improved or new design. The choice of an appropriate constitutive model, which adequately describes the behavior of the material, plays a significant role in the accuracy and reliability of the numerical predictions. Frozen soil presents a very complicated mechanical behavior that exceeds the linear elastic theory and contains plastic, viscoelastic properties and strain softening; the theoretical modeling of the constitutive relation of frozen soils is rather difficult. Therefore, the research on the constitutive relationship of frozen soil is an important subject in the current development of mechanical theory of frozen soil.

Many researches on constitutive theory have been carried out for describing the mechanical behavior of frozen soils. Basing on the Mohr-Coulomb yield criterion, Miao et al. [5] 
TABLE 1: Basic physical parameters of silt.

\begin{tabular}{lcccccc}
\hline \multicolumn{5}{c}{ Composition of particle diameters (\%) } \\
\hline$>0.50 \mathrm{~mm}$ & $0.50 \sim 0.25 \mathrm{~mm}$ & $0.25 \sim 0.10 \mathrm{~mm}$ & $0.10 \sim 0.075 \mathrm{~mm}$ & $0.075 \sim 0.05 \mathrm{~mm}$ & $0.05 \sim 0.005 \mathrm{~mm}$ & $<0.005 \mathrm{~mm}$ \\
0 & 0.792 & 22.798 & 13.50 & 17.15 & 35.93 & 9.83 \\
\hline
\end{tabular}

established a creep microstructure damage theory for frozen soils. Zhu et al. [6] presented an elastic damage constitutive model by regarding frozen soil as composite materials. Yang et al. [7] proposed an elastoplastic nonassociated constitutive model to describe the deformation behavior of frozen soil under high confining pressures. The constitutive models mentioned above could well describe the deformation characteristic of frozen soil under high confining pressure, where the stress-strain curve of frozen soil presents strain hardening behavior. To describe the softening characteristic, the damage evolution behavior in internal structure or complicated formulation of hardening function of frozen soil is regularly considered, which leads to the increase of difficulties in modeling the deformation of frozen soil. Understanding the time-dependent properties of frozen soils is also important to permafrost engineering. Results from creep tests are necessary for the design of most foundation elements embedded in or bearing on artificial frozen ground. They make it possible to predict the time-dependent settlements of piles and shallow foundations under external loads. Lots of achievements on creep constitutive relations were also made as a result of specific conditions of creep process of frozen soil by investigators [8-12]. The present creep formulations are obtained mainly by empirical and element combination theory. Considering that the empirical models were directly derived based on the conventional phenomenological theory, most of the formula's physical meanings are not very definite. The elements-combined model is selected for its simplicity and convenience and the good performance to represent the main deformation behavior of geomaterials [13]. The problems arising from these combinations of classical models cannot reflect accelerated creep property, but can reflect decay creep and equal velocity creep properties of frozen soil. To accurately reproduce the deformation, the researches on constitutive model are still very necessary in the current development of mechanical field of frozen soils.

In this paper, the compression and creep behaviors of frozen silt are investigated through a series of experimental data under different stress levels at a temperature of $-8^{\circ} \mathrm{C}$, respectively. To describe the instaneous deformation of frozen soil, the disturbed state concept and the elliptical surface plasticity model with the associated flow rule were used to characterize the elastoplastic constitutive behavior of frozen soil; to reproduce the time-dependent deformation, a new creep constitutive model of frozen silt is also developed by modifying the generalized Burgers model, and parameters of equations have been obtained by fitting the experimental results. The comparisons between experimental results and prediction from constitutive models show that the proposed constitutive models could describe the deformation behaviors of frozen silt.

\section{Preparation for Samples and Test Results}

2.1. Preparation for Frozen Soil Samples. In this paper, the soil used in test was silt and physical parameters were listed in Table 1. According to the water content of specimen, we weigh the dry silt and the water weight for specimens. Then, a well calculated amount of water was added into the dry silt and mixed thoroughly. After preparation of the mixtures of soil and water, the specimens were prepared in a split mold and consequently were put into the refrigerator to freeze for $48 \mathrm{~h}$. After that, the mold was dismantled and the specimens were subsequently coated by a plastic film and covered by an epoxy resin cap to avoid moisture evaporation. The specimens were prepared as cylinders with $6.18 \mathrm{~cm}$ in diameter and $12.5 \mathrm{~cm}$ in height. After preparation of the specimens, the specimen was placed into the pressure cell of MTS-810 low temperature testing machine for $24 \mathrm{~h}$ at given temperature. Then, the axial pressures were applied on the specimens until reaching the given pressures and kept constant. Experimental procedures are as follows: (i) after the confining and axial pressures had been applied for 5 minutes, the triaxial shear tests began; (ii) when the frozen soil sample was loaded to the given stress level at a constant strain rate of $1.67 \times 10^{-4} \mathrm{~s}^{-1}$, the axial deviatoric stress was kept as a constant value, and deformation behavior was recorded by an automatic data collection system.

2.2. Test Results and Discussions. The experimental curves for triaxial compression and creep tests at $-8^{\circ} \mathrm{C}$ are shown in Figures 1, 2, and 3, respectively.

The experimental results show that the nonlinearity in the stress-strain curves was evident. With regard to this study, the relevant deformation behavior when subjected to compressive loads under different confining pressures can be divided into the following regions. The slope of the stress-axial strain curve is usually found to increase in the early stages of loading due to closure of preexiting cracks. Thereafter, the slopes of stress-strain curves remain relatively constant defining the range of elastic deformation. With the further increase of axial strain, the slopes of the stressstrain curves gradually decrease. The experimental results also indicate that the stress-strain curves of frozen silt are significantly affected by confining pressures. The frozen silt presents strain softening in shear process; with increase of confining pressure, the strain softening characteristic gradually decreases. The slope of stress-strain curve of frozen silt is initially positive but gradually becomes negative with increase of strain. The volumes of frozen silt always reduce with increasing of axial strain at first, but, with a further increasing in axial strain, the volumes expand. The effect of shear dilatation is not obvious under high confining pressure. 


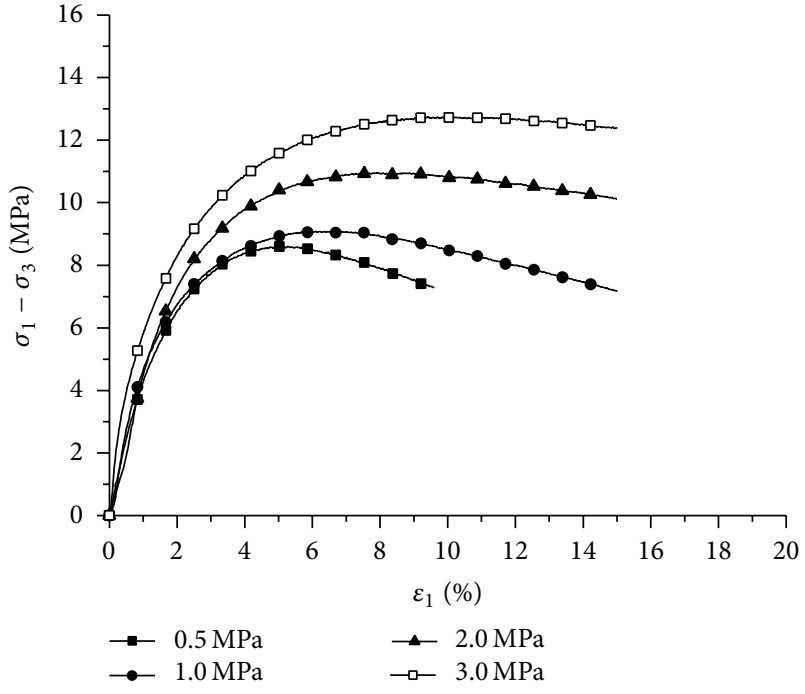

FIgURE 1: The stress-strain curves of frozen silt at $-8^{\circ} \mathrm{C}$.

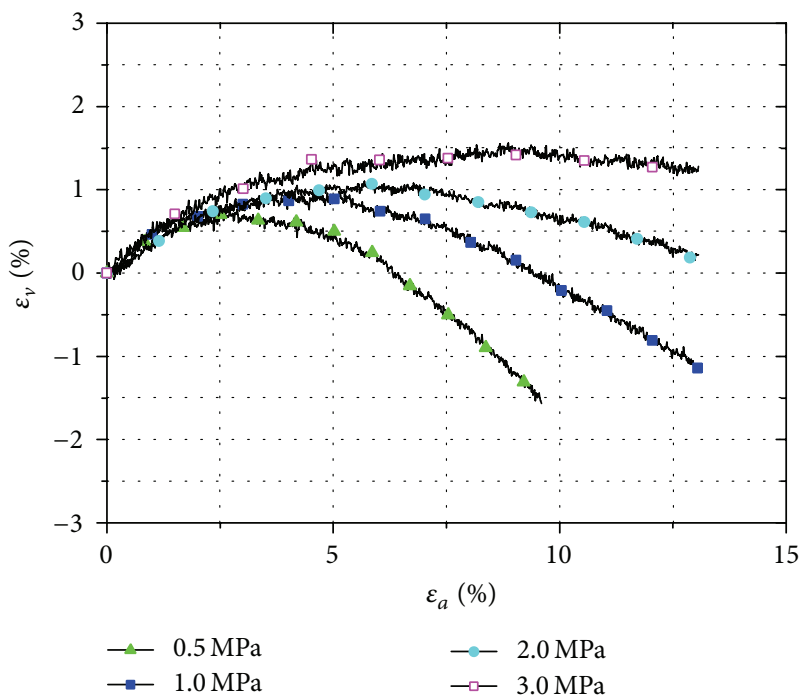

FIGURE 2: The volumetric strain curves of frozen silt at $-8^{\circ} \mathrm{C}$.

Figure 3 presents the strain curves obtained using experimental tests. The experimental results indicate that the creep curves of frozen silt are significantly affected by the stress levels. With the increase in stress level, the creep velocity increases at the same creep time. Generally, the typical creep curves of frozen silt consist of three stages: the decaying creep stage, the stable creep stage, and the accelerating creep stage. In the decaying creep stage, the strain rate of frozen silt is relatively high but slows with increasing time; eventually, the strain rate of frozen silt reaches a minimum and remains nearly constant in the stable creep stage; then the strain rate rapidly increases because of the failure in internal structures of frozen silt in the accelerating creep stage.

\section{Constitutive Models for Frozen Silt}

3.1. Elastic-Plastic Constitutive Model of Frozen Silt. Classical theories of plasticity failed to predict deformation in

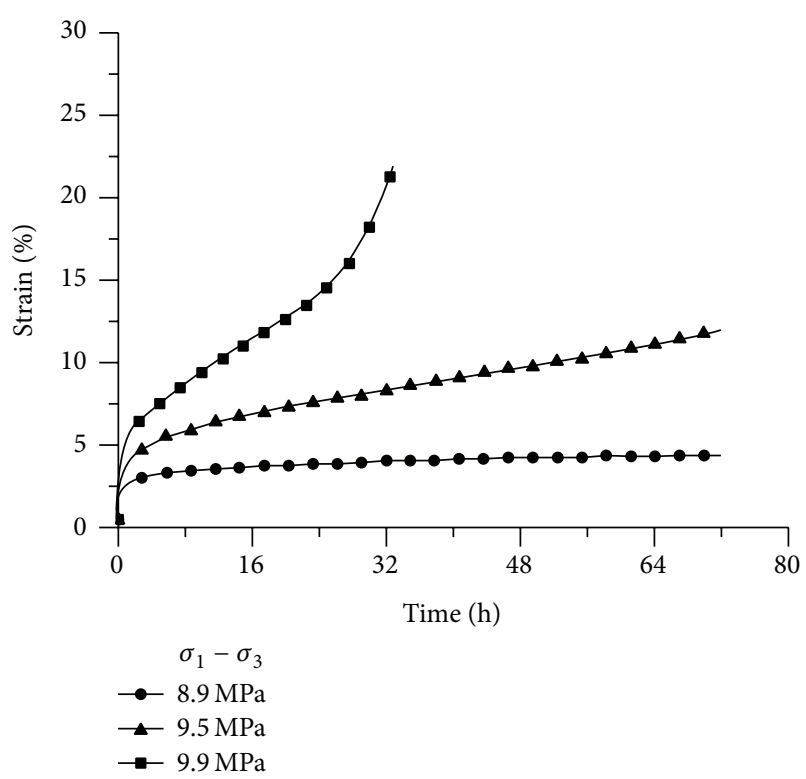

Figure 3: The triaxial creep curves of frozen silt at $-8^{\circ} \mathrm{C}$.

the postcritical regime because an internal length scale was not built into these constitutive relations [14]. To describe the postcritical deformation behavior, the disturbed state model was adopted from various publications [15-18]. The observed behaviors are expressed in terms of RI and FA states using the disturbance function $D$, which acts as a coupling or interaction mechanism between RI and FA states. The RI and FA states of the material are called the reference states. The RI state can be represented by using linear elastic, elastoplastic, or other appropriate models, and the FA state refers to the asymptotic equilibrium state, at which the material tends to the ultimate stages of deformation [19]. Based on the equilibrium of forces, the stress components are the sum of the stress components by the RI portion and those by the FA portion [20]:

$$
\sigma_{i j}=(1-D) \sigma_{i j}^{\mathrm{RI}}+D \sigma_{i j}^{\mathrm{FA}},
$$

where $D$ is the scalar disturbance function.

The disturbance function $D$ is normally evaluated in terms of accumulated plastic stain, the measured stress, work, or nondestructive properties. A useful model for disturbance $D$ can be defined by referring to the internal variable theory method [21]:

$$
D=D_{u}\left(1-e^{-A \xi_{d}^{z}}\right),
$$

where $\xi_{d}$ is the deviatoric plastic strain trajectory and $A, D_{u}$, and $Z$ are material parameters:

$$
\xi_{d}=\int\left(d \varepsilon_{i j}^{p} d \varepsilon_{i j}^{p}\right)^{1 / 2} .
$$

The general form of the basic incremental stress tensor of the DSC model is given by

$$
\begin{gathered}
d \sigma_{i j}=(1-D) d \sigma_{i j}^{\mathrm{RI}}+D d \sigma_{i j}^{\mathrm{FA}}+d D\left(\sigma_{i j}^{\mathrm{FA}}-\sigma_{i j}^{\mathrm{RI}}\right), \\
d D=D_{u} A Z\left(e^{-A \xi_{d}^{Z}}\right) \xi_{d}^{Z-1} d \xi_{d} .
\end{gathered}
$$


In the plastic region, the total strain increment in threedimensional case can be generalized as follows:

$$
d \varepsilon_{i j}=d \varepsilon_{i j}^{e}+d \varepsilon_{i j}^{p}
$$

where $d \varepsilon_{i j}^{e}$ is the elastic strain increment and $d \varepsilon_{i j}^{p}$ is the plastic strain increment.

The plastic strain represents history or path dependence. According to the associated flow rule, the plastic strains can be calculated by

$$
d \varepsilon_{i j}^{p}=d \lambda \frac{\partial g}{\partial \sigma_{i j}}
$$

where $d \lambda$ is a positive scalar which relates to yield function; $g$ is plastic potential function.

Based on the classical plastic theory, the constitutive equation based on the elastoplasticity is generally of the following form:

$$
\begin{gathered}
\{d \sigma\}=[C]_{\mathrm{ep}}\{d \varepsilon\}, \\
\{d \sigma\}=\left\{\begin{array}{l}
d p \\
d q
\end{array}\right\} ; \quad\{d \varepsilon\}=\left\{\begin{array}{l}
d \varepsilon_{v} \\
d \varepsilon_{s}
\end{array}\right\}, \\
{[C]_{\mathrm{ep}}=[C]-\frac{[C]\{\partial g / \partial \sigma\}\{\partial f / \partial \sigma\}^{T}[C]}{A+\{\partial f / \partial \sigma\}^{T}[C]\{\partial g / \partial \sigma\}},}
\end{gathered}
$$

where $[C]$ is the usual matrix of elastic constants, $[C]_{\text {ep }}$ is the elastoplastic constitutive matrix, and $g$ is the plastic potential function.

Consider the plastic deformation is associated with the dissipation of energy so that it is irreversible; the progressive development of the yield surface can be defined by relating the hardening parameter,

$$
\begin{gathered}
W_{p}=\int \sigma_{i j}\left(d \varepsilon_{i j}^{p}\right) \\
A=-\frac{\partial f}{\partial h} \frac{\partial h}{\partial W_{p}}\{\sigma\}^{T}\left\{\frac{\partial g}{\partial \sigma}\right\}=-\frac{\partial f}{\partial h} \frac{\partial h}{\partial W_{p}}\left(\frac{\partial g}{\partial p} p+\frac{\partial g}{\partial q} q\right) .
\end{gathered}
$$

Also, if it is further assumed that the material in the FA state does not carry any stress, (4) can be reduced to

$$
\begin{aligned}
d \sigma_{i j}= & (1-D)\left\{[C]-\frac{[C]\{\partial g / \partial \sigma\}\{\partial f / \partial \sigma\}^{T}[C]}{A+\{\partial f / \partial \sigma\}^{T}[C]\{\partial g / \partial \sigma\}}\right\} \\
& +d D\left(\sigma_{i j}^{\mathrm{FA}}-\sigma_{i j}^{\mathrm{RI}}\right) .
\end{aligned}
$$

To analyze the deformation of frozen silt, we adopt an elliptical yield surface function [22],

$$
f(p, q, h)=g(p, q, h)=\left(\frac{p-h}{k h}\right)^{2}+\left(\frac{q}{k r h}\right)^{2}-1=0,
$$

where $k$ and $r$ are test parameters, which can determine the long and short axes, and $h$ is the hardening parameter, which determines the center of elliptical yield function.
From (11), the hardening parameter $h$ can be obtained as

$$
h=\frac{\sqrt{r^{2} k^{2} p^{2}+\left(k^{2}-1\right) q^{2}}-p r}{r\left(k^{2}-1\right)} .
$$

The hardening parameter could be calculated from the experimental results based on (12), and the relationship curves between hardening parameters $h$ and plastic work $W_{p}$ can be described by the hyperbolic form

$$
h=\frac{a W_{p}}{W_{p}+b}
$$

where $a$ and $b$ are test parameters, which can be obtained from the experimental results.

Dilatation is a special property exhibited by the volume of many soil-like materials and is a phenomenon of considerable interest. In order to describe dilatation behavior of frozen silt, the following equation is adopted in this study [23]:

$$
\frac{d \varepsilon_{v}^{p}}{d \varepsilon_{s}^{p}}=\frac{M p^{2}-q^{2}}{2 p q}
$$

where $M$ is a material constant.

The elastic shear modulus $G$ can be obtained by carrying out loading-unloading-reloading tests under various confining pressures and can be calculated from $q-\varepsilon_{s}$ curves. The relationship between shear modulus $G$ and confining pressure $\sigma_{3}$ can be described by the following formulation:

$$
G=G_{0}+\eta_{g} p_{a} e^{m \sigma_{3} / p_{a}}
$$

where $G_{0}, \eta_{g}$, and $m$ are material parameters; $p_{a}$ is standard atmospheric pressure.

In elastic stage, the relationship between shear elastic modulus $G$ and the volumetric elastic modulus $K$ can be expressed as

$$
K=\frac{2 G(1+\nu)}{3(1-2 \nu)}
$$

The volumetric elastic modulus can be calculated and expressed as follows:

$$
K=K_{0}+\eta_{k} p_{a} e^{m \sigma_{3} / p_{a}}
$$

where $K_{0}, \eta_{k}$ are material constants.

We used the experimental results to illustrate the efficiency and accuracy of the material model; frozen soil compaction process was performed with the following values of the parameters to evaluate the predictive capability of the model. Elasticity parameters were as follows: $G_{0}=1825.6$, $\eta_{g}=44.6 ; m=0.0388, p_{a}=0.10133 \mathrm{~Pa} K_{0}=4462.6$, and $\eta_{k}=109.2$; plastic parameters: $k=9.0 r=0.4, a_{0.5}=0.75$, $b_{0.5}=0.033, a_{3}=6.0 b_{3}=0.067$; disturbance parameters: $A=-35.08, D_{u}=0.011$, and $Z=1.0$; shear expansion parameters: $M_{0.5}=4.5, M_{3}=2.9$.

The results of the calculations using the proposed model are shown in Figure 4. It follows from the obtained results 


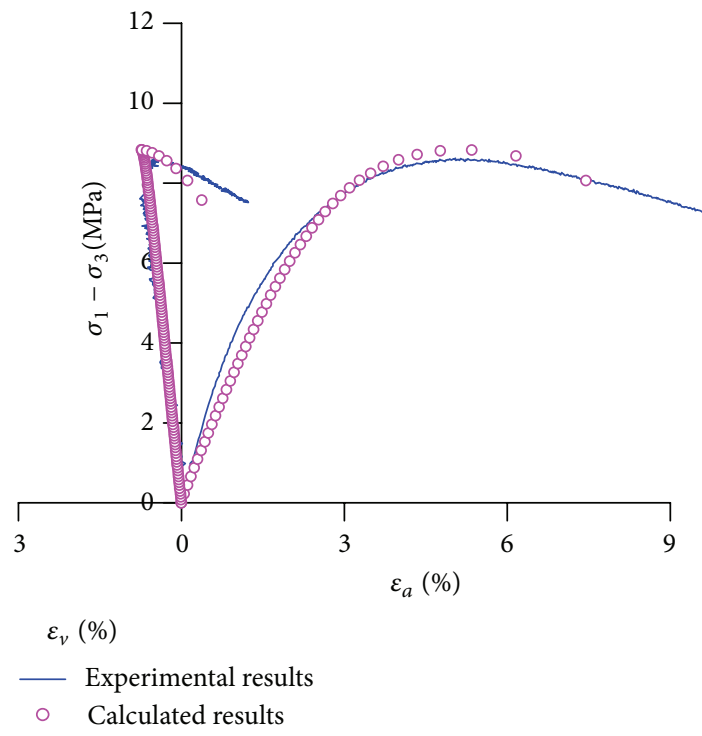

(a) $\sigma_{3}=0.5 \mathrm{MPa}$

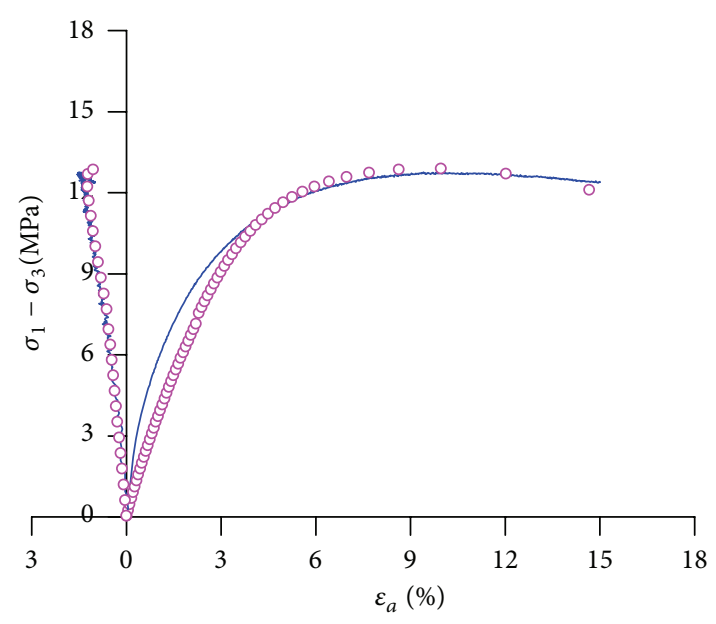

$\varepsilon_{v}(\%)$

— Experimental results

- Calculated results

FIGURE 4: Comparisons between experimental results and calculated results.

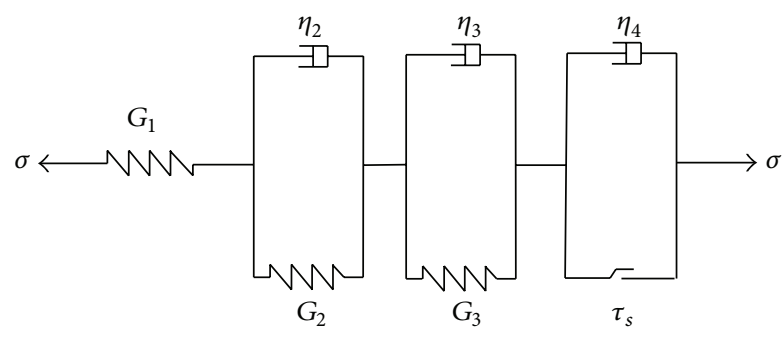

FIGURE 5: Shear creep model of frozen silt.

that there is a general good agreement between the calculated results and the experimental data. The proposed model is able to describe the strain softening features observed in experiments. It also indicates that the disturbed state theory in the context of elastoplasticity can be effectively used for simulating the instaneous deformation of frozen soil under the external load.

3.2. Creep Constitutive Model of Frozen Silt. The macroscopic stress-strain-time behavior can be described using rheological constitutive models, which consists of a combination of elements such as springs, plastic sliders, and dashpots that emulate the basic features of the material behavior. Placing elements in series and/or parallel based on the mechanical properties of the elements and the deformation characteristic of the material, the rheological models can provide a better understanding of the viscoelastic and elastoviscoplastic behaviors [23]. In this study, to ensure a very good description of observed behavior of frozen silt within the range of the first two stages of creeping, the creep model is adopted by adding a Kelvin body into Nishihara's model in series (Figure 5).

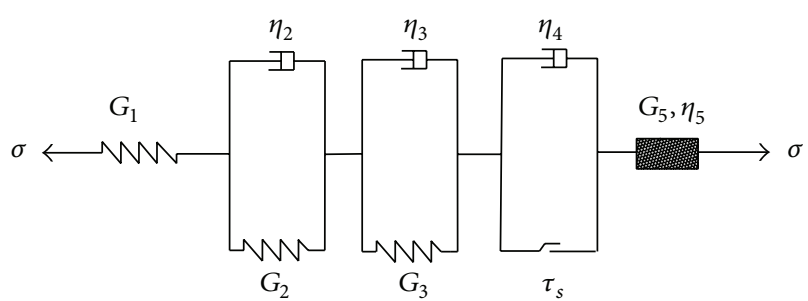

FIgURE 6: Nonlinear shear creep model of frozen silt.

From Figure 5, it can been inferred that, if $0<\tau<\tau_{s}$, the stress-strain relationship can be given by

$$
\begin{gathered}
\tau_{1}=G_{1} \varepsilon_{1}, \quad \tau_{2}=G_{2} \varepsilon_{2}+\eta_{2} \dot{\varepsilon}_{2}, \\
\tau_{3}=G_{3} \varepsilon_{3}+\eta_{3} \dot{\varepsilon}_{3}, \quad \tau=\tau_{1}=\tau_{2}=\tau_{3}, \\
\varepsilon=\varepsilon_{1}+\varepsilon_{2}+\varepsilon_{3},
\end{gathered}
$$

where $G_{1}$ is elastic shear modulus of material; $G_{2}, G_{3}$ are viscoelastic shear moduli; $\eta_{2}, \eta_{3}$ are viscosity coefficient; and $\tau_{s}$ is the shear yield stress of material.

The creep strain versus time dependence can be obtained from (18) as follows:

$$
\varepsilon=\frac{\tau}{G_{1}}+\frac{\tau}{G_{2}}\left[1-\exp \left(-\frac{G_{2}}{\eta_{2}} t\right)\right]+\frac{\tau}{G_{3}}\left[1-\exp \left(-\frac{G_{3}}{\eta_{3}} t\right)\right] .
$$

If $\tau \geq \tau_{s}$, the stress-strain relationship can be obtained as

$$
\begin{aligned}
\varepsilon= & \frac{\tau}{G_{1}}+\frac{\tau}{G_{2}}\left[1-\exp \left(-\frac{G_{2}}{\eta_{2}} t\right)\right] \\
& +\frac{\tau}{G_{3}}\left[1-\exp \left(-\frac{G_{3}}{\eta_{3}} t\right)\right]+\frac{\tau-\tau_{s}}{\eta_{4}} t .
\end{aligned}
$$




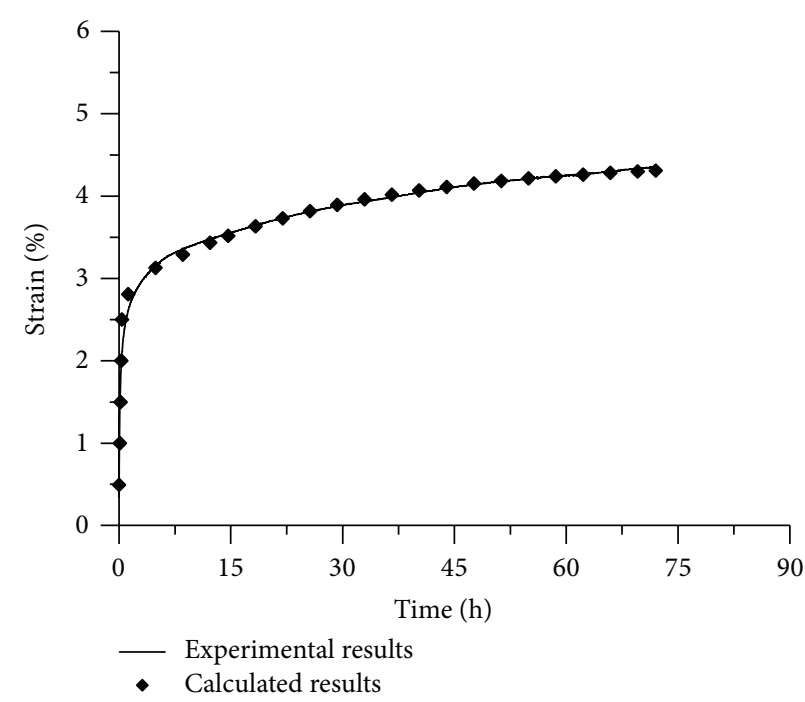

(a) $\sigma_{1}-\sigma_{3}=8.9 \mathrm{MPa}$

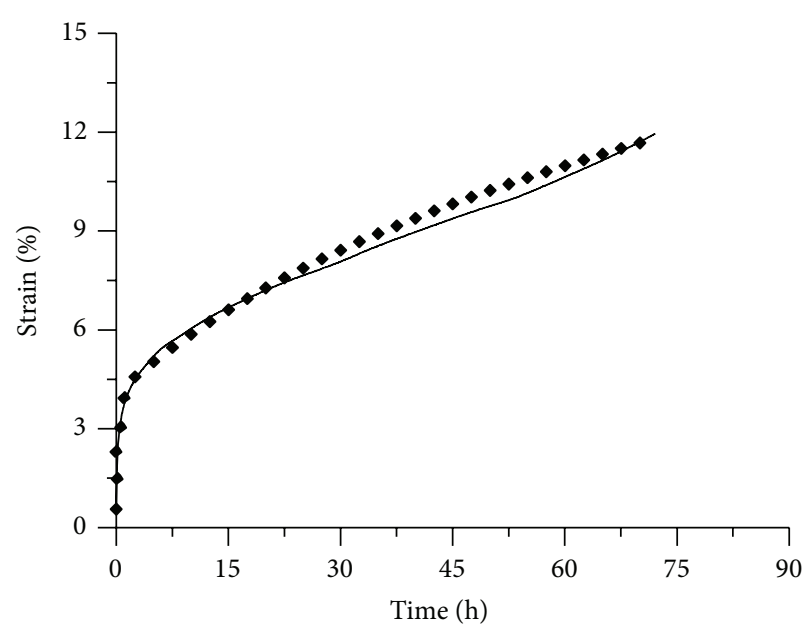

- Experimental results

- Calculated results

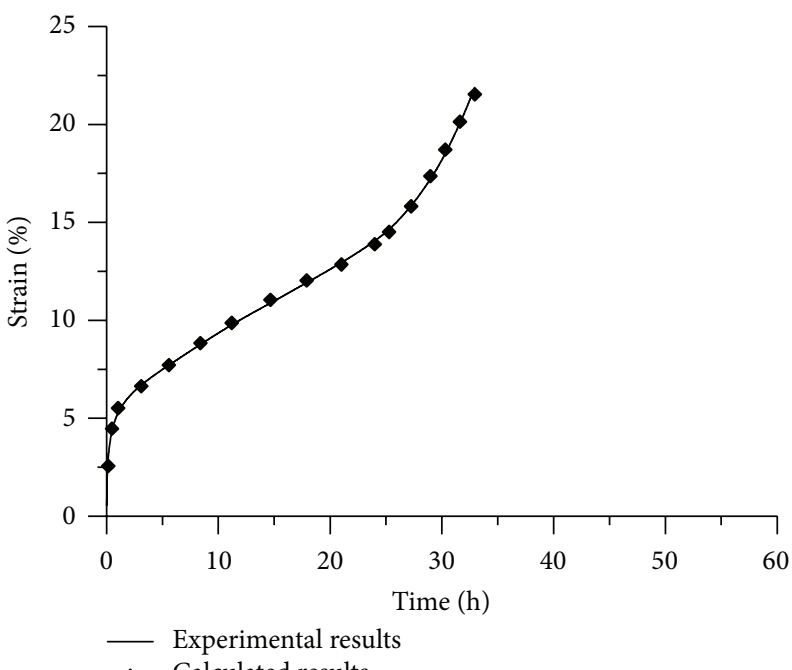

- Calculated results

(c) $\sigma_{1}-\sigma_{3}=9.9 \mathrm{MPa}$

FIGURE 7: Comparisons of creep strain curves between experimental results and calculated results.

The creep constitutive model could not describe the accelerated stage of frozen soil by adopting the traditional elements. To describe the accelerated stage of rock material, a nonlinear rheology element has been presented by [24]; the formulation is given as follows:

$$
\mathcal{E}(t)=\frac{\tau}{G}\left[1-e^{\left[H\left(t-t_{2}\right) /\left(t_{c}-t_{2}\right)\right]^{n}}\right]
$$

where $G, n$ are rheological parameters; $t_{2}$ is the initial time of accelerated creep stage; $t_{c}$ is the creep rupture time of material; $H\left(t-t_{2}\right)$ is a positive function and determines the creep rate of material at the accelerated creep stage. The function $H\left(t-t_{2}\right)$ can be expressed as

$$
H\left(t-t_{2}\right)= \begin{cases}0 & \left(t \leq t_{2}\right) \\ t-t_{2} & \left(t>t_{2}\right)\end{cases}
$$

To ensure a very good description of observed behavior of the frozen silt within the entire creep process, a new creep constitutive model is established by adding the nonlinear rheology element mentioned above into the original creep model in series (Figure 6).

Based on the understanding of creep mechanisms of frozen silt, a new constitutive equation has been formulated by element combination theory,

$$
\begin{aligned}
\varepsilon= & \frac{\tau}{G_{1}}+\frac{\tau}{G_{2}}\left[1-\exp \left(-\frac{G_{2}}{\eta_{2}} t\right)\right]+\frac{\tau}{G_{3}}\left[1-\exp \left(-\frac{G_{3}}{\eta_{3}} t\right)\right] \\
& +\frac{\tau-\tau_{s}}{\eta_{4}} t+\frac{\tau}{G_{5}}\left[1-e^{\left[H\left(t-t_{2}\right) /\left(t_{c}-t_{2}\right)\right]^{n}}\right] .
\end{aligned}
$$


TABLE 2: Parameters of nonlinear shear creep model for frozen silt.

\begin{tabular}{lcccccccc}
\hline$\sigma_{1}-\sigma_{3} / \mathrm{MPa}$ & $G_{1} / \mathrm{MPa}$ & $G_{2} / \mathrm{MPa}$ & $\eta_{2} / \mathrm{MPah}$ & $G_{3} / \mathrm{MPa}$ & $\eta_{3} / \mathrm{MPah}$ & $\eta_{4} / \mathrm{MPa}$ & $\tau_{s} / \mathrm{MPa}$ & $G_{5} / \mathrm{MPa}$ \\
\hline 8.9 & 2000 & 366.5 & 155.7 & 576.1 & 15617.9 & - & - & - \\
9.5 & 2000 & 262.3 & 94.4 & 229.7 & 6524.7 & 553.9 & 9.2 & - \\
9.9 & 2000 & 211.0 & 64.2 & 59.1 & 2046.0 & 17095.5 & 9.2 & 106.1 \\
\hline
\end{tabular}

The proposed creep model is now used to simulate some typical laboratory tests to check its validity, and the whole creep processes both for low and for high stress levels of frozen silt are calculated using the values of parameters given in Table 2, and some representative results are shown in Figure 7.

Figure 7 shows the creep strain curves obtained by both computation and experiment, and a good agreement between the calculated results and experimental data both for low and for high stress levels can be seen. The influence of stress level on the creep behavior of frozen silt is correctly predicted by the proposed model.

\section{Conclusions}

To research stability of construction in the artificial frozen soil engineering, the triaxial compression and creep behaviors of frozen soil are investigated through a series of experimental data at a temperature of $-8^{\circ} \mathrm{C}$.

The test results showed that frozen silt presents strain softening in shear process under low confining pressures, but strain softening phenomenon decreases with increase of confining pressures. In order to reproduce the instaneous deformation behavior of frozen silt, a disturbed state constitutive model is developed and verified. The comparisons between experimental results and predictions from the constitutive model show that the disturbed state model could well reflect the conventional triaxial compression.

The creep curves mainly present the decaying and the stable creep stages under low stress levels. However, under high stress levels, once the strain increases to critical value, the creep strain velocity gradually increases and the specimen quickly happens to destroy. Based on the creep results, a new creep constitutive model is established to describe the entire creep process of frozen silt.

\section{Conflict of Interests}

The authors declare that there is no conflict of interests regarding the publication of this paper.

\section{Acknowledgments}

The authors would like to thank very much the anonymous reviewers whose constructive comments are helpful for this paper's revision. This research was supported by the National Natural Science Foundation of China (51204161), the Fundamental Research Funds for the Central Universities (2012QNA57), and the National Natural Science Foundation of China (51323004).

\section{References}

[1] G. X. Cui, "Mechanics of frozen soil for deep alluvium- a new field of frozen soil mechanics," Journal of Glaciology and Geocryology, vol. 20, no. 2, pp. 97-100, 1998.

[2] W. Ma and X. Chang, "Analyses of strength and deformation of an artificially frozen soil wall in underground engineering," Cold Regions Science and Technology, vol. 34, no. 1, pp. 11-17, 2002.

[3] D.-Y. Wang, W. Ma, X.-X. Chang, and A.-G. Wang, "Study on the resistance to deformation of artificially frozen soil in deep alluvium," Cold Regions Science and Technology, vol. 42, no. 3, pp. 194-200, 2005.

[4] J. W. Kaspar, "Constitutive models for engineering materials," Encyclopedia of Physical Science and Technology, vol. 3, pp. 603633, 2002.

[5] T. D. Miao, X. X. Wei, and C. Q. Zhang, "A study on creep of frozen soil by damage mechanics," Science in China B, vol. 25, no. 3, pp. 309-317, 1995.

[6] Z. W. Zhu, J. G. Ning, and S. C. Song, "Finite-element simulations of a road embankment based on a constitutive model for frozen soil with the incorporation of damage," Cold Regions Science and Technology, vol. 62, no. 2-3, pp. 151-159, 2010.

[7] Y. Yang, Y. Lai, Y. Dong, and S. Li, “The strength criterion and elastoplastic constitutive model of frozen soil under high confining pressures," Cold Regions Science and Technology, vol. 60, no. 2, pp. 154-160, 2010.

[8] B. Ladanyi and G. H. Johnston, "Evaluation of in situ creep properties of frozen soils with the pressure-meter," in Proceedings of the 2nd International Permafrost Conference, pp. 310-317, Yakutsk, Russia, 1973.

[9] A. M. Fish, "Creep and strength of frozen soil under triaxial compression," Cold Regions Research and Engineering Laboratory, vol. 94, no. 32, 1994.

[10] S. S. Vyalov and A. S. Khamed, "Creep and long-term strength of clayey soils in triaxial compression," Soil Mechanics and Foundation Engineering, vol. 34, no. 1, pp. 9-14, 1997.

[11] X. Zhang, S. Zhang, Y. Li, and B. Huo, "Testing study on triaxial creep properties of frozen soil to determine thickness of frozen wall," Chinese Journal of Rock Mechanics and Engineering, vol. 23, no. 3, pp. 395-400, 2004.

[12] S.-P. Zhao, P. He, Y.-L. Zhu, and X.-X. Chang, "Comparison between dynamic and static creep characteristics of frozen silt," Chinese Journal of Geotechnical Engineering, vol. 28, no. 12, pp. 2160-2163, 2006.

[13] Y. Qi, Q. Jiang, Z. Wang, and C. Zhou, “3D creep constitutive equation of modified Nishihara model and its parameters identification," Chinese Journal of Rock Mechanics and Engineering, vol. 31, no. 2, pp. 347-355, 2012.

[14] J. T. Zhang and J. Yang, "Advance in micromechanical constitutive theories and modeling in asphalt mixture: a review," in Proceedings of the 13th COTA International Conference of Transportation Professionals, pp. 1304-1314, 2013. 
[15] C. S. Desai and J. Toth, "Disturbed state constitutive modeling based on stress-strain and nondestructive behavior," The International Journal of Solids and Structures, vol. 33, no. 11, pp. 16191650, 1996.

[16] M. D. Liu, J. P. Carter, C. S. Desai, and K. J. Xu, "Analysis of the compression of structured soils using the disturbed state concept," International Journal for Numerical and Analytical Methods in Geomechanics, vol. 24, pp. 723-735, 2000.

[17] A. H. Akhaveissy and C. S. Desai, "Application of the DSC model for nonlinear analysis of reinforced concrete frames," Finite Elements in Analysis and Design, vol. 50, pp. 98-107, 2012.

[18] C. S. Desai, Mechanics of Materials and Interfaces: The Disturbed State Concept, CRC Press, Boca Raton, Fla, USA, 2001.

[19] A. H. Akhaveissy and C. S. Desai, "Application of the DSC model for nonlinear analysis of reinforced concrete frames," Finite Elements in Analysis and Design, vol. 50, pp. 98-107, 2012.

[20] S. M. Sane, C. S. Desai, J. W. Jenson, D. N. Contractor, A. E. Carlson, and P. U. Clark, "Disturbed State constitutive modeling of two Pleistocene tills," Quaternary Science Reviews, vol. 27, no. 3-4, pp. 267-283, 2008.

[21] C. S. Desai and W. Zhang, "Computational aspects of disturbed state constitutive models," Computer Methods in Applied Mechanics and Engineering, vol. 151, no. 3-4, pp. 361-376, 1998.

[22] W. X. Huang, J. L. Pu, and Y. J. Chen, "Hardening rule and yield function for soils," in Proceedings of the 10th International Conference on Soil Mechanics and Foundation Engineering, 1981.

[23] M. Chi and C. Zhao, "Dilatant model of sand based on the CamClay model," Journal of Beijing Jiaotong University, vol. 32, no. 1, pp. 49-53, 2008.

[24] S. Q. Yang, H. M. Ni, and S. H. Yu, "A kind of nonlinear rheological model for rocks," Journal of Hohai University, vol. 35, no. 4, pp. 388-392, 2007. 

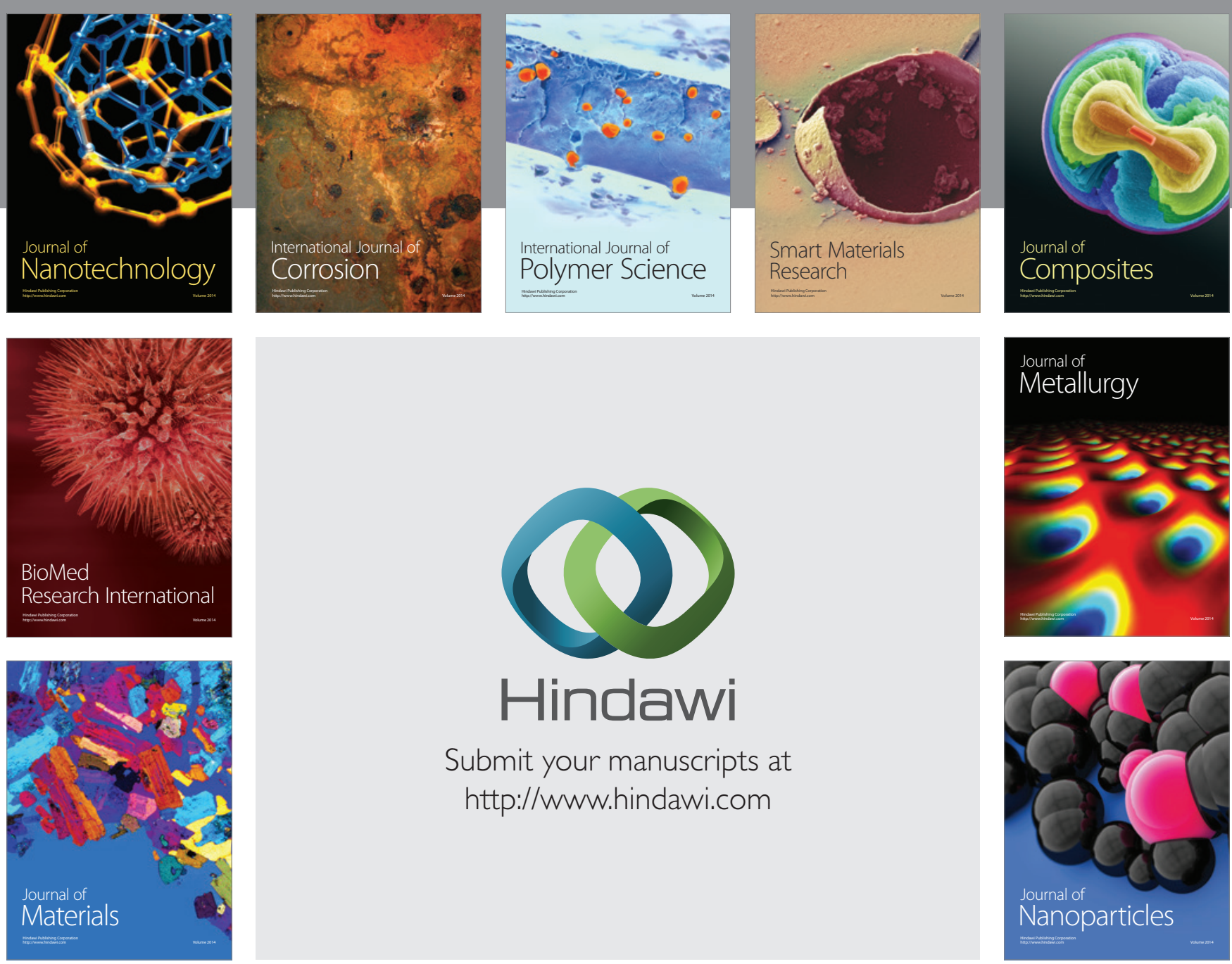

Submit your manuscripts at http://www.hindawi.com
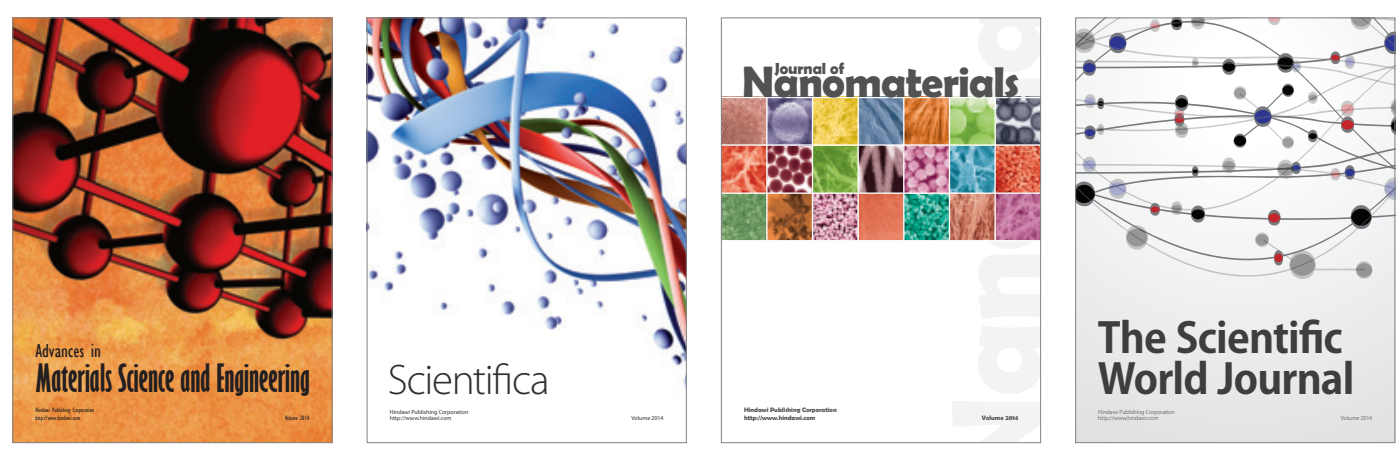

\section{The Scientific World Journal}
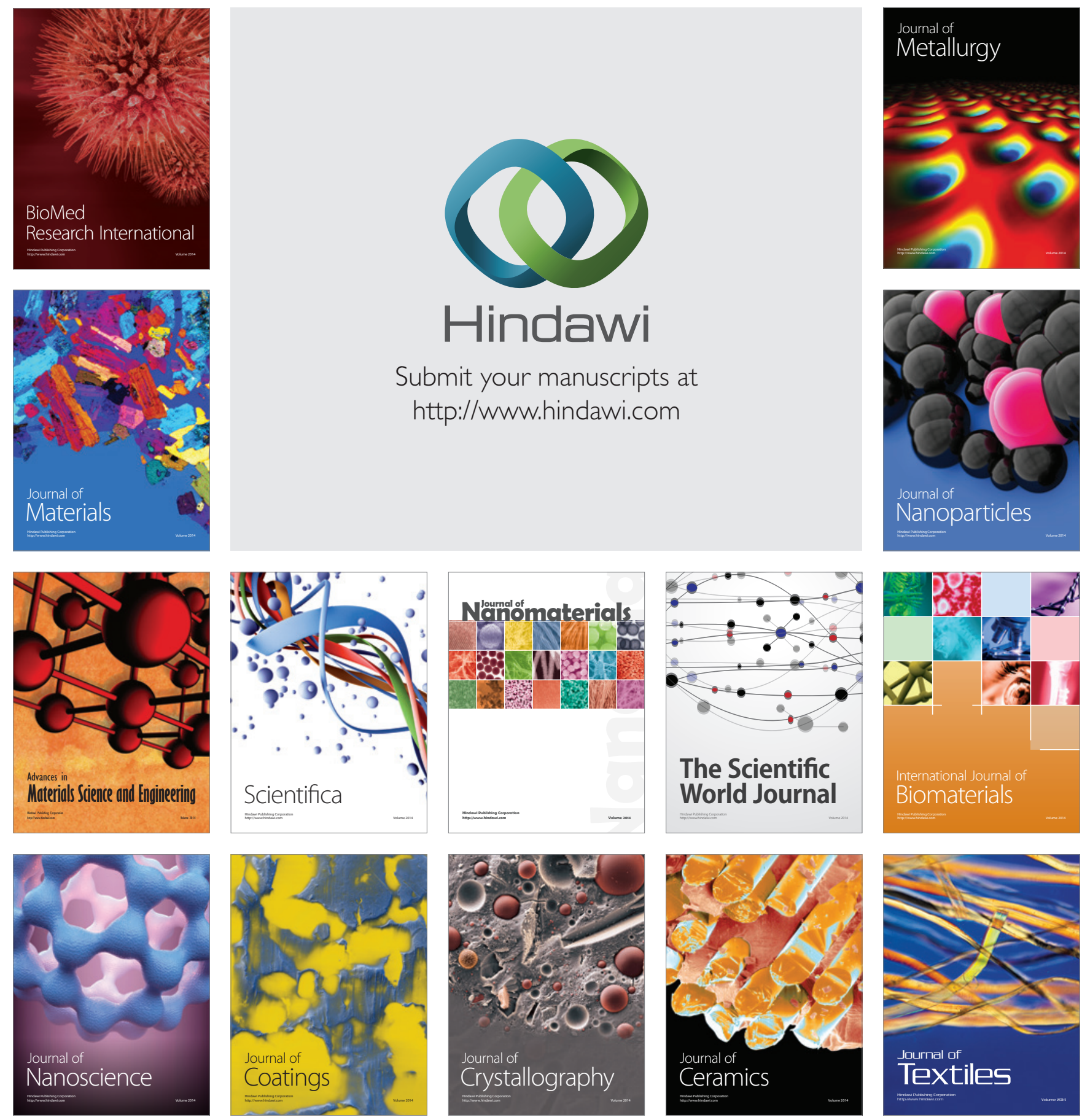